Article

\title{
Damping Analysis of Some Inorganic Particles on Poly(butyl-methacrylate)
}

\author{
Saisai Zhou ${ }^{1}$, Chunhua Yang ${ }^{1}$, Jia Hu ${ }^{1}$, Xianru He ${ }^{1, *}$ and Rui Zhang ${ }^{2, *}$ \\ 1 School of Materials Science and Engineering, Southwest Petroleum University, Chengdu 610500, China; \\ 201621000041@stu.swpu.edu.cn (S.Z.); 201721000028@stu.swpu.edu.cn (C.Y.); \\ 201531053301@stu.swpu.edu.cn (J.H.) \\ 2 Institute für Physik, Universität Rostock, Albert-Einstein-Str. 23-24, 18051 Rostock, Germany \\ * Correspondence: xrhe@swpu.edu.cn (X.H.); rui.zhang@uni-rosotck.de (R.Z.)
}

Received: 10 May 2018; Accepted: 9 June 2018; Published: 12 June 2018

check for updates

\begin{abstract}
Viscoelastic polymers can be used as damping materials to control unexpected vibration and noise through energy dissipation. To investigate the effect of an inorganic filler on damping property, a series of inorganic particles, Ferriferous oxide $\left(\mathrm{Fe}_{3} \mathrm{O}_{4}\right)$, Graphene $/ \mathrm{Fe}_{3} \mathrm{O}_{4}(\mathrm{GF})$, and $\mathrm{Fe}_{3} \mathrm{O}_{4}$ of demagnetization $\left(\alpha-\mathrm{Fe}_{2} \mathrm{O}_{3}\right)$ were incorporated into poly(butyl-methacrylate) (PBMA). The effects of the dispersion of particles, as well as the interaction between particles and the PBMA matrix on the damping property of composites, were systematically studied. Results revealed that the addition of three types of particles can effectively improve the damping properties and broaden the effective damping temperature range. Dispersion of $\alpha-\mathrm{Fe}_{2} \mathrm{O}_{3}$ in the PBMA matrix is better than that of $\mathrm{Fe}_{3} \mathrm{O}_{4}$. As a result, the damping peak can be increased more. The interaction between GF and the PBMA matrix is stronger than that between $\mathrm{Fe}_{3} \mathrm{O}_{4}$ and the PBMA. The damping peak of the composites can be suppressed by GF, which is opposite to $\mathrm{Fe}_{3} \mathrm{O}_{4}$ and $\alpha-\mathrm{Fe}_{2} \mathrm{O}_{3}$. In addition, glass transition temperature $\left(\mathrm{T}_{\mathrm{g}}\right)$ of all composites in the study shifted to low temperatures.
\end{abstract}

Keywords: poly(butyl-methacrylate); inorganic particles; damping property; glass transition temperature

\section{Introduction}

With the development of modern technology, all kinds of mechanical equipment are developing high speed, high efficiency, and automation, but vibration and noise, which are produced during work, seriously damage the reliability and stability of the machine itself [1,2]. Passive or active damping are extremely effective ways for, mostly, vibration control [3,4]. Passive vibration control involves the modification of the stiffness and damping of a vibrating system. A straightforward and effective solution for vibration and noise control is the application of a viscoelastic material, such as polymers [5]. Because of its high damping characteristics around the glass temperature, viscoelastic polymer is usually used as a damping material to control noise and vibration, which has attracted considerable attention [6]. The loss tangent $(\tan \delta)$, which is the ratio of $E^{\prime \prime}$ to $E^{\prime}\left(\tan \delta=E^{\prime \prime} / E^{\prime}\right)$, is used as an assessment of the ability to dissipate energy by elastomers. $E^{\prime}$ and $E^{\prime \prime}$ represent the storage modulus and loss modulus, respectively [7]. High-performance viscoelastic damping materials should meet the requirement of $\tan \delta>0.3$ over a broad damping temperature range of at least $60-80{ }^{\circ} \mathrm{C}$ [8].

Matrix polymers must be considered according to the application and environment in which the material is to be applied [9]. Polyacrylate materials are well known for their excellent damping properties for plenty of polar ester groups $[10,11]$ and PBMA has an excellent adhesion property, with its macromolecular chain having many branched chains, which can effectively increase internal friction and improve damping properties. A great efforts have been devoted to broaden the effective damping temperature range of acrylic polymers, including co-polymers, interpenetrating polymer 
networks (IPN), and blends [12-14]. One of the most important ways is blends consisting of adding filler with modifications.

$\mathrm{Fe}_{3} \mathrm{O}_{4}$ (ferriferrous oxide), in our previous study, was found to have a strong interaction with ethylene vinyl acetate (EVA), which has polar vinyl acetate (VA) segments $[15,16]$. $\mathrm{Fe}_{3} \mathrm{O}_{4}$, theoretically, should also have strong interactions with PBMA because of its polar carbanyl groups. So, after hybridization with $\mathrm{Fe}_{3} \mathrm{O}_{4}$, the particles will have interactions with PBMA, which can make a great contribution to mechanical loss [17]. However, it is easy for $\mathrm{Fe}_{3} \mathrm{O}_{4}$ particles to aggregate due to magnetism between particles $[18,19]$. Thus, the dispersion state of particles in the matrix and the interactions between particles and the matrix are very important for damping properties of composites. To improve the dispersion of $\mathrm{Fe}_{3} \mathrm{O}_{4}$ in the PBMA matrix, $\mathrm{Fe}_{3} \mathrm{O}_{4}$ particles of demagnetization were prepared in high temperatures $[20,21]$. Moreover, to study the effect of fillers-matrixes interactions on the damping properties of $\mathrm{PBMA}, \mathrm{Fe}_{3} \mathrm{O}_{4}$ and graphene $/ \mathrm{Fe}_{3} \mathrm{O}_{4}$ hybrid particles were incorporated into PBMA. These two particles have a distinguishable interaction with PBMA, since they have different interfaces. Graphene, with a two-dimensional layer, prevents $\mathrm{Fe}_{3} \mathrm{O}_{4}$, with three-dimensional sphere shape, from aggregating. Meanwhile, due to the magnetism of graphene [22], it is easier for $\mathrm{Fe}_{3} \mathrm{O}_{4}$ to load graphene as the core.

In this article, to study the effects of the dispersion of particles, as well as the interactions between particles and the PBMA matrix on damping property of composites, $\mathrm{Fe}_{3} \mathrm{O}_{4}$, Graphene $/ \mathrm{Fe}_{3} \mathrm{O}_{4}(\mathrm{GF}$ ), and $\alpha-\mathrm{Fe}_{2} \mathrm{O}_{3}$ are incorporated into PBMA. The elemental analysis, morphology, and specific surface area of graphene hybrid particles are analyzed by energy dispersive spectrometer (EDS), scanning electron microscopy (SEM), and specific surface area and pore size tester, respectively. The structures, particle size, and magnetization of $\mathrm{Fe}_{3} \mathrm{O}_{4}$ of demagnetization $\left(\alpha-\mathrm{Fe}_{2} \mathrm{O}_{3}\right)$ are characterized by $\mathrm{X}$-ray diffraction (XRD), laser particle size analyzer, and vibrating sample magnetometer analysis (VSM). The dynamic mechanical analysis (DMA) and scanning electron microscopy (SEM) are used to characterize the damping materials. It is expected to find far-ranging applications as damping materials in vibration control.

\section{Materials and Methods}

PBMA $\left(\mathrm{M}_{\mathrm{W}}=504631, \mathrm{PDI}=8.186\right)$ was synthesized by free radical emulsion polymerization in our laboratory. $\mathrm{Fe}_{3} \mathrm{O}_{4}$ particles were synthesized by the procedure reported previously in Ref. [15]. Pristine graphene (number of layers, 1-10) was provided by Deyang Carbonene Co., Ltd (Deyang, China). $\mathrm{Fe}_{3} \mathrm{O}_{4}$ of demagnetization $\left(\alpha-\mathrm{Fe}_{2} \mathrm{O}_{3}\right)$ were obtained by heating $\mathrm{Fe}_{3} \mathrm{O}_{4}$ particles up to $500{ }^{\circ} \mathrm{C}$ (under air atmosphere). Sodium dodecyl benzene sulfonate, sodium persulfate, ferric trichloride, Ferrous sulfate, sodium hydroxide, and polyvinyl alcohol were all purchased from Chengdu Kelong Chemical Reagent Factory (Chengdu, China). The reagents were analytical grade.

\subsection{Synthesis of Graphene/ $/ \mathrm{Fe}_{3} \mathrm{O}_{4}$ Hybrid Particles}

First, $0.2 \mathrm{~g}$ of pristine graphene was added into a $\mathrm{NaOH}$ (sodium hydroxide) aqueous solution $(0.1 \mathrm{~mol} / \mathrm{L})$ and heated to $80{ }^{\circ} \mathrm{C}$ with vigorous stirring. Then $\mathrm{FeCl}_{3} \cdot 6 \mathrm{H}_{2} \mathrm{O}$ and $\mathrm{FeSO}_{4} \cdot 7 \mathrm{H}_{2} \mathrm{O}$ were dissolved in a PVA aqueous solution to prepare the mixed solution of iron ions with 2:1 molar ratio of $\mathrm{Fe}^{3+}$ to $\mathrm{Fe}^{2+}$, then $200 \mathrm{~mL}$ mixed solution of iron ions was dropped slowly into the $\mathrm{NaOH}$ aqueous solution with graphene through a constant pressure drop funnel at $80^{\circ} \mathrm{C}$ in a water bath. The reaction continued for $40 \mathrm{~min}$ and the black precipitates were washed with alcohol and deionized water for at least five times, followed by freeze drying at $50{ }^{\circ} \mathrm{C}$ for $96 \mathrm{~h}$.

\subsection{Preparation of Samples of Poly(butyl-methacrylate)-Based Hybrid Material}

Blends of PBMA with different particle contents were prepared via solution mixing at room temperature for $15 \mathrm{~min}$. The basic formulation of the composites is listed in Table 1; the blends were compression molded to form sheets ( $20 \mathrm{~mm}$ long, $12 \mathrm{~mm}$ wide, and $3 \mathrm{~mm}$ thick) under a pressure of $10 \mathrm{MPa}$ for $20 \mathrm{~min}$ at $160{ }^{\circ} \mathrm{C}$. 
Table 1. Formulations of poly (butyl-methacrylate) inorganic particles composites.

\begin{tabular}{cc}
\hline Material & Weight (g) \\
\hline $\mathrm{PBMA}$ & $19.9 / 19.8 / 19.6 / 19.0$ \\
$\mathrm{Fe}_{3} \mathrm{O}_{4}$ & $0.1 / 0.2 / 0.4 / 1.0$ \\
$\alpha-\mathrm{Fe}_{2} \mathrm{O}_{3}$ & $0.1 / 0.2 / 0.4 / 1.0$ \\
$\mathrm{GF}$ & $0.1 / 0.2 / 0.4 / 1.0$ \\
\hline
\end{tabular}

\subsection{Characterization}

X-ray diffraction (XRD, X Pert PRO MPD, Almelo, the Netherlands) was used to test the crystal structure of $\mathrm{Fe}_{3} \mathrm{O}_{4}$. The scanning range was from $5^{\circ}$ to $70^{\circ}$ and the scanning speed was $3.6^{\circ} / \mathrm{min}$.

Particle sizes were characterized by Laser Particle Size Analyzer (Master sizer 2000, Malvern Instruments Ltd., Malvern, UK), ethanol was used as a dispersant, and the shade was 3.5\%.

The specific surface areas were tested by a specific surface area and pore size tester (ST-MP-9, Quantachrome Instruments, Beijing, China). The test results were analyzed by the multipoint Brunauer-Emmet-Teller (BET) method. Before the test, samples were kept at $423 \mathrm{~K}$ in a vacuum environment for about $2 \mathrm{~h}$.

VSM (BKT-4500Z, Quantum Design Ltd., San Diego, CA, USA) was carried out to measure the saturated magnetic strengths of particles, in open circuit mode at normal temperature.

The morphology of the poly(butyl-methacrylate)-based composite material was studied by scanning electron microscopy (SEM; ZEISS EV0 MA15, Carl Zeiss microscopy Co., Ltd., Jena, Germany). To prepare samples for SEM analysis, the composites were quenched in liquid nitrogen and cryogenically fractured.

Elemental analysis was carried out at Energy Dispersive Spectrometer (EDS; Elementar, Langenselbold, Germany) for determination of the $\mathrm{Fe}, \mathrm{O}$ and $\mathrm{C}$ content.

Dynamic mechanical analysis (DMA) was carried out on Q800 (TA Instruments, New Castle, DE, USA) by using a dual cantilever clamp and a testing method of temperature ramp-frequency sweep with a frequency of $1 \mathrm{~Hz}$. The samples were trimmed to dimensions of $20 \mathrm{~mm}$ long, $12 \mathrm{~mm}$ wide and $3 \mathrm{~mm}$ thick. The oscillation strain amplitude was set to be $15 \mathrm{~mm}$.

\section{Results and Discussion}

\subsection{Morphologies and EDS of Graphene $/ \mathrm{Fe}_{3} \mathrm{O}_{4}$ Hybrid Particles}

The morphology of the GF composite particle is shown in Figure 1a. As we can see, GF presents a near-spherical shape. $\mathrm{Fe}_{3} \mathrm{O}_{4}$ particles, as the core and most of the particle surface, are surrounded by graphene sheets. To further testify the structure of GF, the GF particle was analyzed by energy dispersive spectrometer. Figure $1 \mathrm{~b}-\mathrm{d}$ are the mapping images of iron, oxygen, and carbon elements, respectively. The above discussion indicates that Graphene and $\mathrm{Fe}_{3} \mathrm{O}_{4}$ particle was compounded when available.
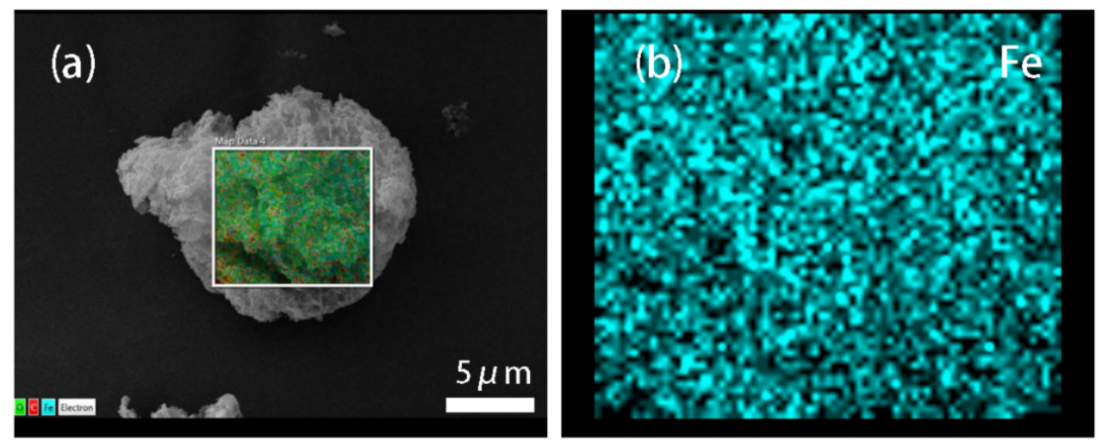

Figure 1. Cont. 

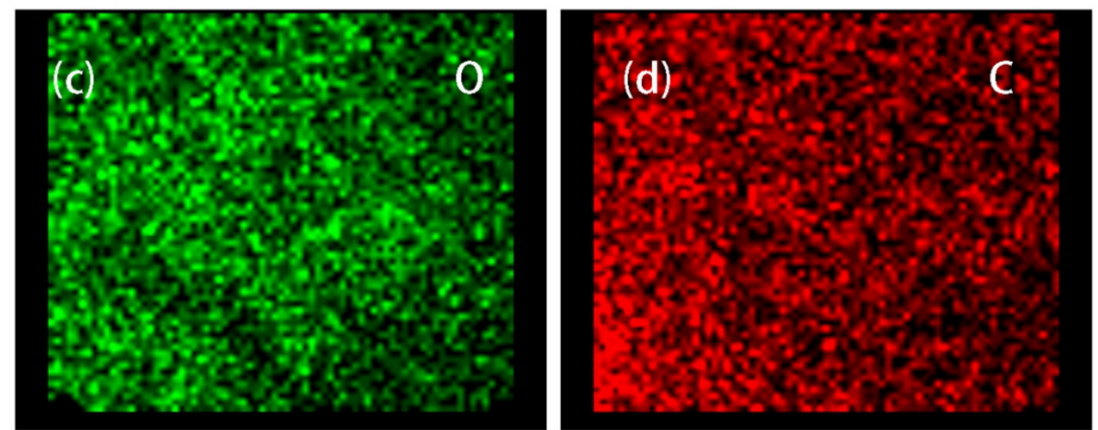

Figure 1. (a) SEM images of Graphene $/ \mathrm{Fe}_{3} \mathrm{O}_{4} ;(\mathbf{b}-\mathbf{d})$ iron, oxygen, and carbon mapping images of Graphene $/ \mathrm{Fe}_{3} \mathrm{O}_{4}$.

\subsection{Demagnetization of $\mathrm{Fe}_{3} \mathrm{O}_{4}$}

As reported in the literature, a high temperature is commonly used for demagnetization [21]. Demagnetization of $\mathrm{Fe}_{3} \mathrm{O}_{4}\left(\alpha-\mathrm{Fe}_{2} \mathrm{O}_{3}\right)$ was obtained by heating $\mathrm{Fe}_{3} \mathrm{O}_{4}$ particles up to $500{ }^{\circ} \mathrm{C}$ (under air atmosphere) to improve the dispersion of $\mathrm{Fe}_{3} \mathrm{O}_{4}$ in the PBMA matrix. The magnetic properties of $\mathrm{Fe}_{3} \mathrm{O}_{4}$ and $\alpha-\mathrm{Fe}_{2} \mathrm{O}_{3}$ were studied by a vibrating sample magnetometer at room temperature. As shown in Figure 2, $\mathrm{Fe}_{3} \mathrm{O}_{4}$ presents the highest magnetization and $\alpha-\mathrm{Fe}_{2} \mathrm{O}_{3}$ shows the lowest magnetization after heating at $500{ }^{\circ} \mathrm{C}$.

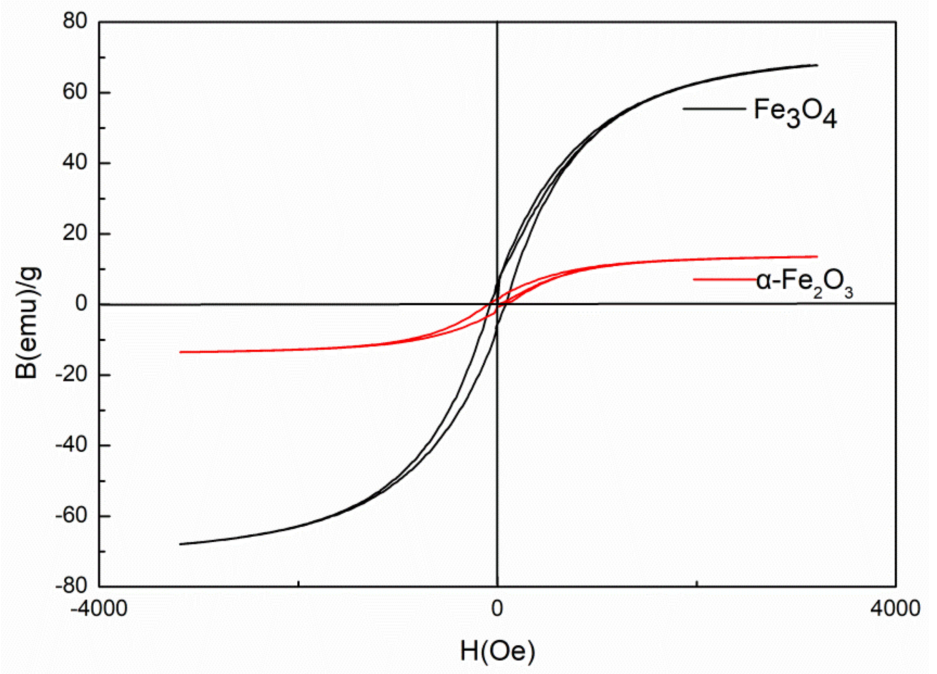

Figure 2. Magnetic hysteresis loops of $\mathrm{Fe}_{3} \mathrm{O}_{4}$ and $\alpha-\mathrm{Fe}_{2} \mathrm{O}_{3}$.

As shown in Figure 3, the accordance between the peak positions of XRD patterns and ICDS cards of $\mathrm{Fe}_{3} \mathrm{O}_{4}$ and $\alpha-\mathrm{Fe}_{2} \mathrm{O}_{3}$ particles were proved. And the XRD patterns are in coherence with ICDS cards of, pdf \# 74-0748 $\left(\mathrm{Fe}_{3} \mathrm{O}_{4}\right)$ and pdf \# 79-0007 $\left(\alpha-\mathrm{Fe}_{2} \mathrm{O}_{3}\right)$. The results reveal that crystal form of $\mathrm{Fe}_{3} \mathrm{O}_{4}$ with heating is changed, while its own chemical composition is in accord with that of $\alpha-\mathrm{Fe}_{2} \mathrm{O}_{3}$.

Moreover, the values of particle size are listed in Table 2. The particle size of $\alpha-\mathrm{Fe}_{2} \mathrm{O}_{3}$ quite close to that of $\mathrm{Fe}_{3} \mathrm{O}_{4}$, which further indicates that the interaction between the two particles and matrix is similar. 


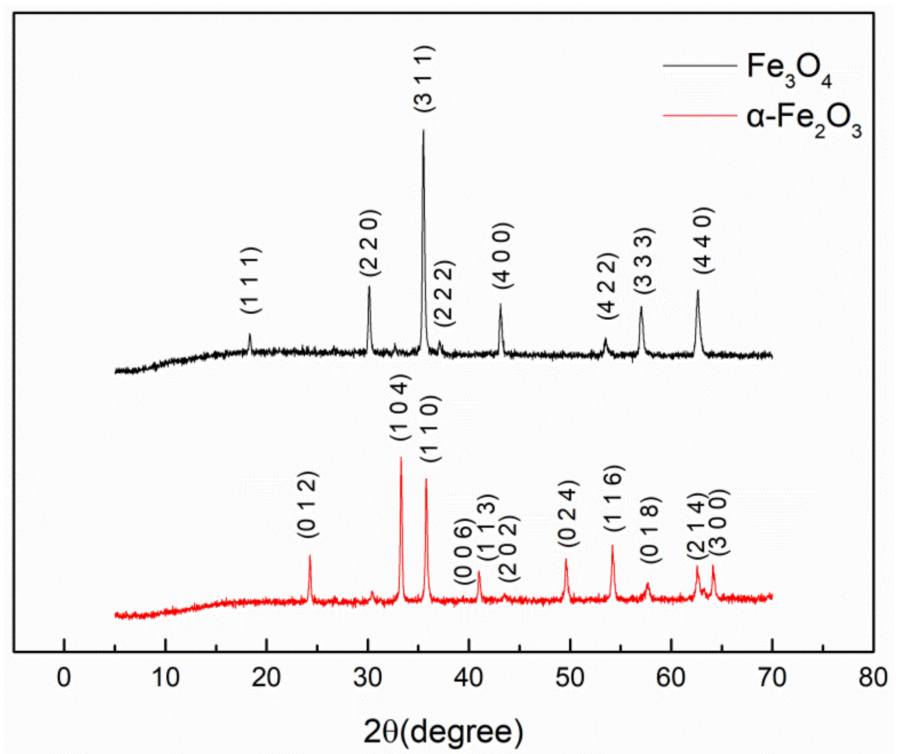

Figure 3. XRD patterns of $\mathrm{Fe}_{3} \mathrm{O}_{4}$ and $\alpha-\mathrm{Fe}_{2} \mathrm{O}_{3}$. Particles were indexed according to the standard of ICDS Cards, 74-0748 and 79-0007 for $\mathrm{Fe}_{3} \mathrm{O}_{4}$ and $\alpha-\mathrm{Fe}_{2} \mathrm{O}_{3}$, respectively.

Table 2. Value of particle size.

\begin{tabular}{cc}
\hline Sample & d (0.5) \\
\hline $\mathrm{Fe}_{3} \mathrm{O}_{4}$ & $2.202 \mu \mathrm{m}$ \\
$\alpha-\mathrm{Fe}_{2} \mathrm{O}_{3}$ & $2.110 \mu \mathrm{m}$ \\
\hline
\end{tabular}

\subsection{Morphology}

The dispersion of the fillers was researched by SEM measurements on the brittle and snapped sample surface. As shown in Figure 4, in PBMA/ $\mathrm{Fe}_{3} \mathrm{O}_{4}$ composites, the dispersion of $\mathrm{Fe}_{3} \mathrm{O}_{4}$ and their interfacial interactions with the PBMA matrix are critical for the damping properties of the composites. The dispersion of $\mathrm{Fe}_{3} \mathrm{O}_{4}$ in the PBMA matrix was homogeneous when $0.5 \% \mathrm{Fe}_{3} \mathrm{O}_{4}$ was added. When the content of $\mathrm{Fe}_{3} \mathrm{O}_{4}$ was beyond $1 \%$, the damping properties decreased slightly because of the aggregation of $\mathrm{Fe}_{3} \mathrm{O}_{4}$ (Figure $4 \mathrm{c}, \mathrm{d}$ ). $\alpha-\mathrm{Fe}_{2} \mathrm{O}_{3}$ particles, after high temperature demagnetization, have good dispersibility in the PBMA matrix, as shown in Figure 4e. When the GF was added into the PBMA matrix, the dispersion of them was relatively homogeneous.
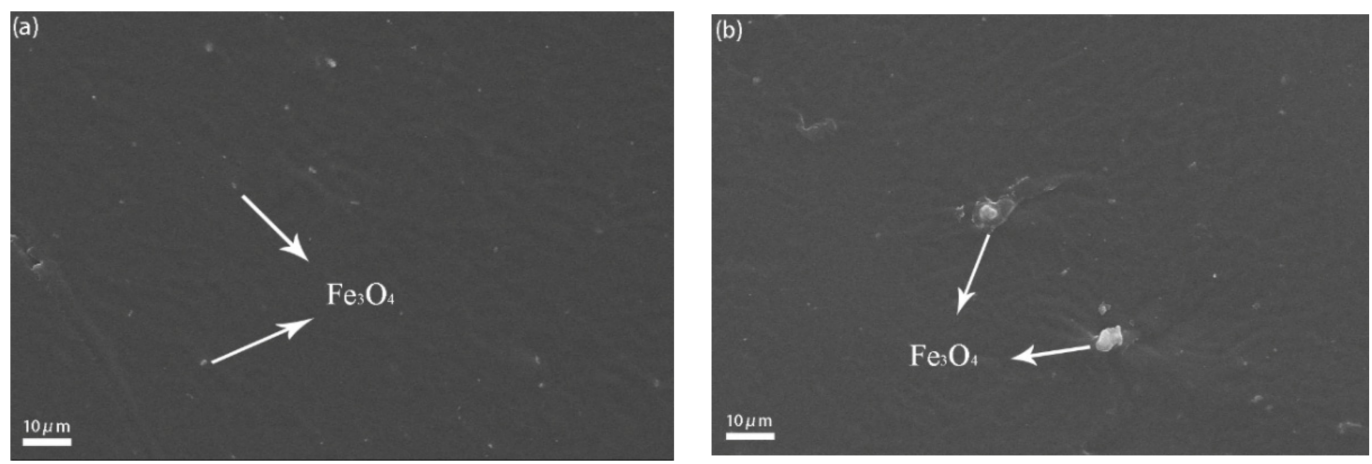

Figure 4. Cont. 

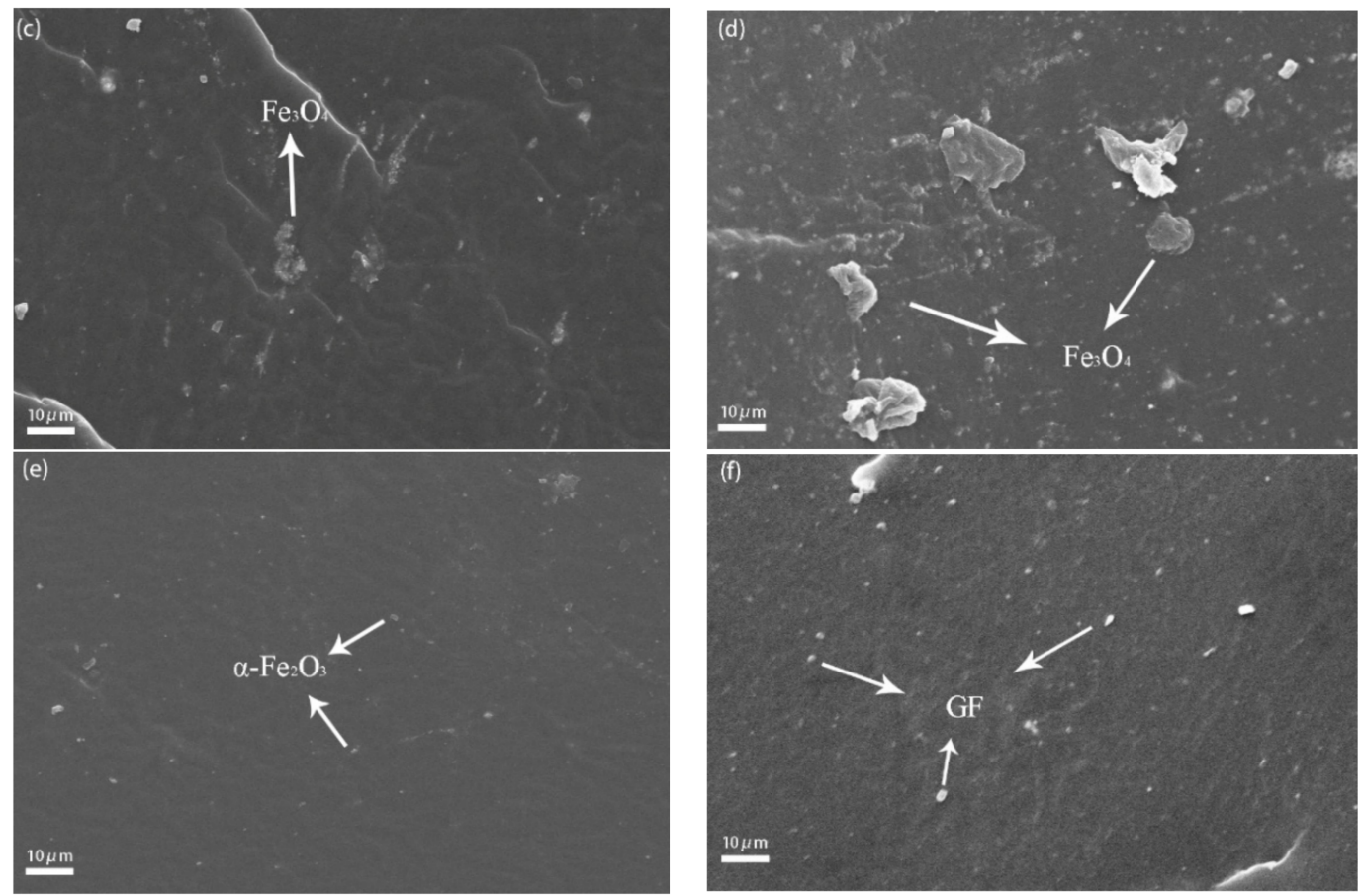

Figure 4. SEM images of (a) PBMA $/ 0.5 \% \mathrm{Fe}_{3} \mathrm{O}_{4}$ composites; (b) $\mathrm{PBMA} / 1 \% \mathrm{Fe}_{3} \mathrm{O}_{4}$ composites; (c) $\mathrm{PBMA} / 2 \% \mathrm{Fe}_{3} \mathrm{O}_{4}$ composites; (d) PBMA $/ 5 \% \mathrm{Fe}_{3} \mathrm{O}_{4}$ composites; (e) PBMA $/ 1 \% \alpha-\mathrm{Fe}_{2} \mathrm{O}_{3}$ composites;

(f) $\mathrm{PBMA} / 1 \%$ GF composites.

\subsection{Damping Property of $\mathrm{PBMA} / \mathrm{Fe}_{3} \mathrm{O}_{4}$ and $\mathrm{PBMA} / \alpha-\mathrm{Fe}_{2} \mathrm{O}_{3}$}

Dynamic mechanical analysis (DMA) is widely used to determine material damping properties as functions of temperature, frequency, and stress [23] and to investigate the effect of an increasing content of inorganic particles on the damping properties of PBMA/ $/ \mathrm{Fe}_{3} \mathrm{O}_{4}$ and PBMA $/ \alpha-\mathrm{Fe}_{2} \mathrm{O}_{3}$. Results of the DMA tests are presented in the form of loss factor, $\tan \delta$, as functions of temperature.

Curves of the variations of $\tan \delta$ with the temperature of $\mathrm{Fe}_{3} \mathrm{O}_{4}$ and $\alpha-\mathrm{Fe}_{2} \mathrm{O}_{3}$ composites are shown in Figures 5 and 6, respectively. The loss tangent ( $\tan \delta$ ) is commonly called damping and is the evaluation measure of energy dissipation. The values of the maximum heights versus the loads of particles are shown by Figure 6. As is seen, $\mathrm{Fe}_{3} \mathrm{O}_{4}$ and $\alpha-\mathrm{Fe}_{2} \mathrm{O}_{3}$ show similar influences on the maximum heights of $\tan \delta$.
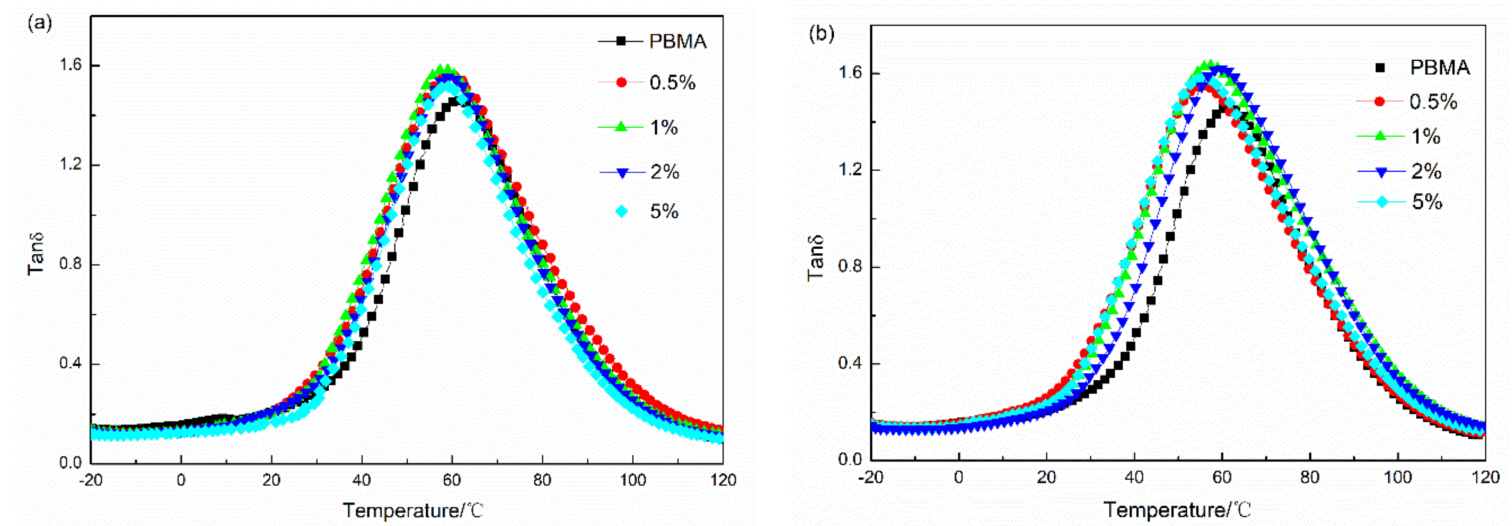

Figure 5. Temperature dependence spectra of $\tan \delta$ of PBMA with different particles and different mass fraction at $1 \mathrm{~Hz}$. (a) $\mathrm{Fe}_{3} \mathrm{O}_{4} ;\left(\right.$ b) $\alpha-\mathrm{Fe}_{2} \mathrm{O}_{3}$. 


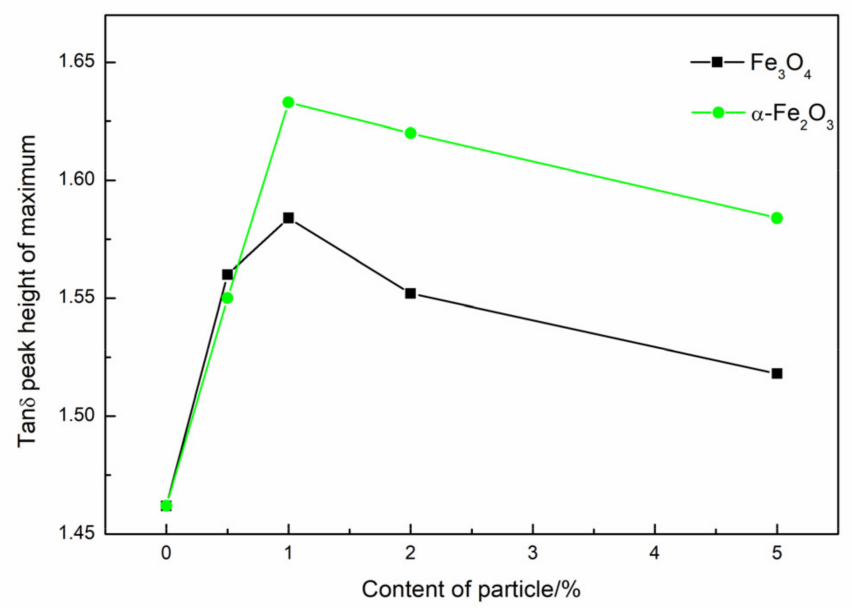

Figure 6. Effect of the content of inorganic particles on the peak height of PBMA blends.

For $\mathrm{Fe}_{3} \mathrm{O}_{4}$, the maximum heights increased at first and then decreased; the largest points of maximum heights were located when the mass fraction of $\mathrm{Fe}_{3} \mathrm{O}_{4}$ was $1 \%$. When $\mathrm{Fe}_{3} \mathrm{O}_{4}$ were added to the composites, internal friction between $\mathrm{Fe}_{3} \mathrm{O}_{4}$ and polymer chains, as well as friction between $\mathrm{Fe}_{3} \mathrm{O}_{4}$ particles, increased the rate of the dissipating energy. The damping properties were improved. The damping properties decreased slightly when the content of $\mathrm{Fe}_{3} \mathrm{O}_{4}$ was beyond $1 \%$ due to the aggregation of $\mathrm{Fe}_{3} \mathrm{O}_{4}$ decreasing the internal friction of the composites. Table 3 shows that all PBMA $/ \mathrm{Fe}_{3} \mathrm{O}_{4}$ blends have efficient damping $(\tan \delta>0.3)$ over a wide temperature range of more than $64{ }^{\circ} \mathrm{C}$. Moreover, the peak area under the $\tan \delta$ temperature curves is abbreviated as TA, which is a measure of the energy dissipation of a transition process [24]. The TA values of $\mathrm{PBMA} / \mathrm{Fe}_{3} \mathrm{O}_{4}$ composites are also summarized in Table 3. Compared with blank PBMA, PBMA $/ \mathrm{Fe}_{3} \mathrm{O}_{4}$ composites exhibit relatively high TA values.

Table 3. The damping properties of $\mathrm{PBMA} / \mathrm{Fe}_{3} \mathrm{O}_{4}$ and $\mathrm{PBMA} / \alpha-\mathrm{Fe}_{2} \mathrm{O}_{3}$ blends.

\begin{tabular}{|c|c|c|c|c|c|c|}
\hline \multirow{2}{*}{$\begin{array}{l}\text { Sample Code } \\
\mathrm{PBMA} / \mathrm{Fe}_{3} \mathrm{O}_{4}\end{array}$} & \multicolumn{2}{|c|}{ Tan $\delta$ Max } & \multicolumn{3}{|c|}{ Temperature Range of Tan $\delta>0.3$} & \multirow[t]{2}{*}{ TA $(\operatorname{Tan} \delta>1.0)$} \\
\hline & Value & $\mathrm{T} /{ }^{\circ} \mathrm{C}$ & $\mathrm{T}_{1} /{ }^{\circ} \mathrm{C}$ & $\mathrm{T}_{2} /{ }^{\circ} \mathrm{C}$ & $\Delta \mathrm{T} /{ }^{\circ} \mathrm{C}$ & \\
\hline $0 \%$ & 1.46 & 61.19 & 30.80 & 98.00 & 67.20 & 7.39 \\
\hline $0.5 \%$ & 1.56 & 59.66 & 26.87 & 100.83 & 73.96 & 10.59 \\
\hline $1 \%$ & 1.58 & 57.72 & 28.30 & 97.97 & 69.67 & 10.58 \\
\hline $2 \%$ & 1.55 & 59.06 & 28.43 & 97.02 & 68.59 & 9.21 \\
\hline $5 \%$ & 1.52 & 58.63 & 30.84 & 94.86 & 64.02 & 8.08 \\
\hline \multicolumn{7}{|l|}{$\mathrm{PBMA} / \alpha-\mathrm{Fe}_{2} \mathrm{O}_{3}$} \\
\hline $0 \%$ & 1.46 & 61.19 & 30.80 & 98.00 & 67.20 & 7.39 \\
\hline $0.5 \%$ & 1.55 & 55.3 & 22.79 & 98.34 & 75.55 & 10.59 \\
\hline $1 \%$ & 1.63 & 56.81 & 25.19 & 103.00 & 77.81 & 13.43 \\
\hline $2 \%$ & 1.62 & 59.05 & 27.83 & 102.51 & 74.68 & 12.71 \\
\hline $5 \%$ & 1.58 & 55.58 & 25.16 & 99.80 & 74.64 & 11.74 \\
\hline
\end{tabular}

The glass transition temperature $\left(\mathrm{T}_{\mathrm{g}}\right)$ of the composites, taken at the maximum value of the $\tan \delta$, is determined by the DMA $[25,26]$. As observed from Figure 5 a, increasing the mass fraction of $\mathrm{Fe}_{3} \mathrm{O}_{4}$ shifted the curve peak to low temperatures, with the incorporation of $1 \% \mathrm{Fe}_{3} \mathrm{O}_{4}$ into the PBMA matrix leading to the greatest decrease in $\mathrm{T}_{\mathrm{g}}$, referring to neat PBMA. This phenomenon can be interpreted as follows: With the inclusion of $\mathrm{Fe}_{3} \mathrm{O}_{4}$ into PBMA, the $\mathrm{Fe}_{3} \mathrm{O}_{4}$ particles interact with and shield carbanyl groups and, as a result, a lowered $\mathrm{T}_{\mathrm{g}}$ was observed.

For $\alpha-\mathrm{Fe}_{2} \mathrm{O}_{3}$, to improve the dispersion of $\mathrm{Fe}_{3} \mathrm{O}_{4}$ in the PBMA matrix in the present study, demagnetization of $\mathrm{Fe}_{3} \mathrm{O}_{4}\left(\alpha-\mathrm{Fe}_{2} \mathrm{O}_{3}\right)$ was incorporated into the PBMA. The maximum $\tan \delta$ of 
PBMA $/ \alpha-\mathrm{Fe}_{2} \mathrm{O}_{3}$ increased and the temperature range with $\tan \delta>0.3$ became wider, as shown in Figure $5 b$ and Table 3. The damping properties of the composites improved. Moreover, when the weight content of $\alpha-\mathrm{Fe}_{2} \mathrm{O}_{3}$ was $1 \%$, the tan $\delta$ reached 1.63 , and the corresponding temperature range, with $\tan \delta>0.3$, was about $103{ }^{\circ} \mathrm{C}$. The results show the demagnetization of $\mathrm{Fe}_{3} \mathrm{O}_{4}\left(\alpha-\mathrm{Fe}_{2} \mathrm{O}_{3}\right)$ could increase the internal friction due to homogeneous dispersion of $\alpha-\mathrm{Fe}_{2} \mathrm{O}_{3}$ in the PBMA matrix (Figure 4e). Moreover, $\mathrm{T}_{\mathrm{g}}$ of the $\alpha-\mathrm{Fe}_{2} \mathrm{O}_{3}$ composites shifts to low temperature as seen from Figure $5 \mathrm{~b}$ and it is more obvious to shift to low temperature comparing to $\mathrm{Fe}_{3} \mathrm{O}_{4}$ composites.

\subsection{Damping Property of PBMA/GF}

As shown in Figure 7, the loss tangent, $\tan \delta$, of PBMA/GF composites increased compared with neat PBMA. However, Figure 7 and Table 4 demonstrated that the damping factor of PBMA/GF composites is lower than that of $\mathrm{PBMA} / \mathrm{Fe}_{3} \mathrm{O}_{4}$ composites, although, $\mathrm{Fe}_{3} \mathrm{O}_{4}$ particles with a modified surface can better disperse in the PBMA matrix. These results are because the interfacial interaction in PBMA/GF hybrids is stronger than that in the PBMA/ $\mathrm{Fe}_{3} \mathrm{O}_{4}$ hybrids, as shown in Table 3. The adhering of $\mathrm{Fe}_{3} \mathrm{O}_{4}$ to graphene, as shown in Figure 1, changes the interaction surfaces between particles and molecular chains that interact between $\mathrm{Fe}_{3} \mathrm{O}_{4}$ and $\mathrm{PBMA}$ and become the interaction between graphene and PBMA. GF particles have a larger specific surface area, as shown in Figure 8, which enhances interaction between GF and PBMA, thus, resulting in lower internal friction.

It is interesting that the glass transition temperature of PBMA/GF composites also shifts to low temperatures. The results are attributed to $\mathrm{Fe}_{3} \mathrm{O}_{4}$ adhering to graphene, which changes the interaction surfaces between particles and molecular chains as mentioned above. Moreover, graphene is a typical two-dimensional layered material. The layered structure is held together by van der Walls interactions, shown in Figure 1. An intercalation state or, even, exfoliation state of fillers is possibly formed due to the weak van der Walls interactions between adjacent layers. Furthermore, the layer of two-dimensional layered fillers could slip to some extent [27]. For example, Jiang et al. [28] prepared chlorinated butyl rubber/graphene oxide composites (CIIR/GO) and proposed a slippage of the lamellae to interpret the results that the $\mathrm{T}_{\mathrm{g}}$ of CIIR/GO composites shifts towards low temperatures. The mechanism is also used to interpret our case in that the slippage of the lamellae could increase the mobility of PBMA chains so that the glass transition temperatures of PBMA/GF hybrids shift towards low temperatures.

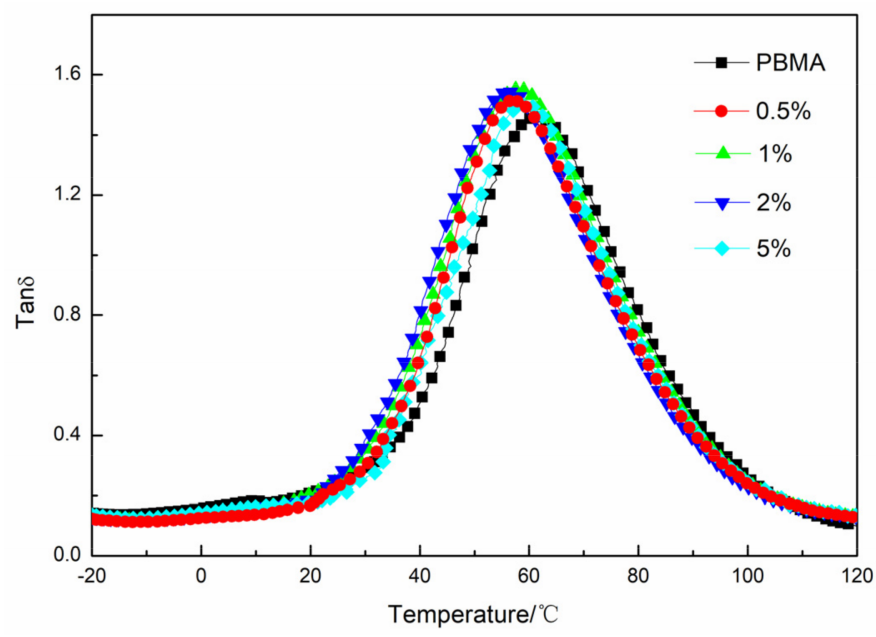

Figure 7. The temperature dependence of loss tangent $(\tan \delta)$ at $1 \mathrm{~Hz}$ for PBMA and PBMA/GF. 
Table 4. The damping properties of PBMA/GF.

\begin{tabular}{|c|c|c|c|c|c|c|}
\hline \multirow{2}{*}{$\begin{array}{c}\text { Sample Code } \\
\text { PBMA/GF }\end{array}$} & \multicolumn{2}{|c|}{ Tan $\delta$ Max } & \multicolumn{3}{|c|}{ Temperature Range of Tan $\delta>0.3$} & \multirow[t]{2}{*}{ TA $(\operatorname{Tan} \delta>1.0)$} \\
\hline & Value & $\mathrm{T} /{ }^{\circ} \mathrm{C}$ & $\mathrm{T}_{1} /{ }^{\circ} \mathrm{C}$ & $\mathrm{T}_{2} /{ }^{\circ} \mathrm{C}$ & $\Delta \mathrm{T} /{ }^{\circ} \mathrm{C}$ & \\
\hline $0.5 \%$ & 1.52 & 56.88 & 30.13 & 95.68 & 65.55 & 8.11 \\
\hline $1 \%$ & 1.55 & 57.63 & 27.95 & 96.36 & 68.41 & 9.78 \\
\hline $2 \%$ & 1.54 & 55.95 & 27.08 & 94.68 & 67.60 & 9.27 \\
\hline $5 \%$ & 1.50 & 58.72 & 33.74 & 96.12 & 62.38 & 7.80 \\
\hline
\end{tabular}
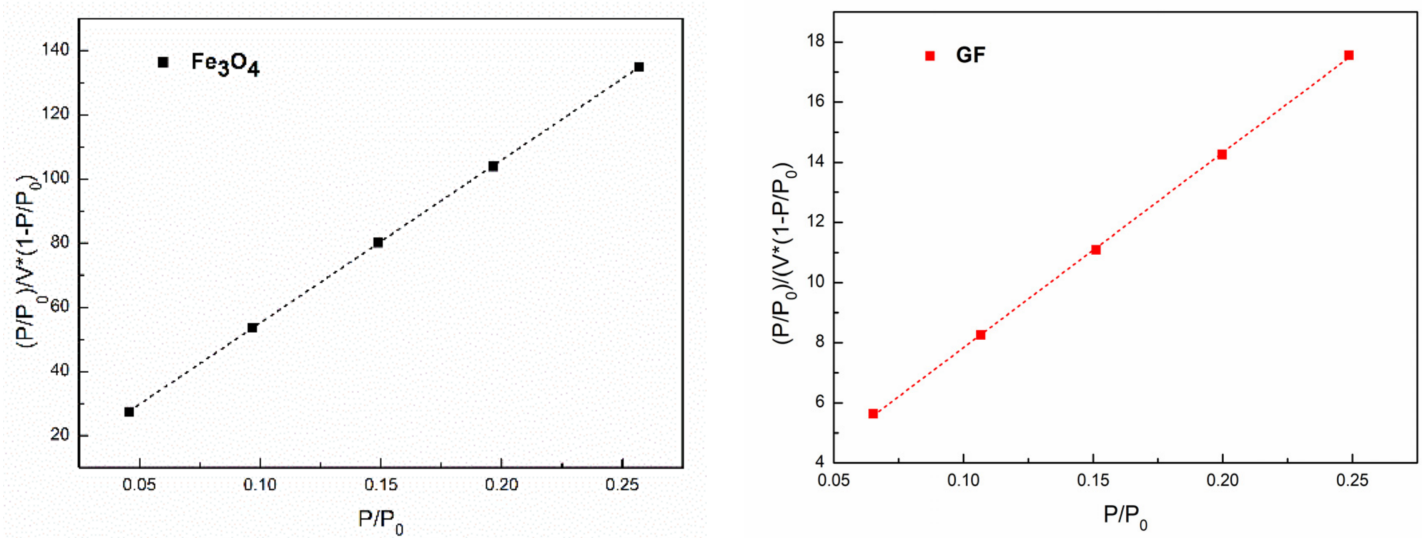

Figure 8. Brunauer-Emmet-Teller (BET) spectra of $\mathrm{Fe}_{3} \mathrm{O}_{4}$ and GF measured by a specific surface area and pore size tester. Fitting index, $R^{2}=0.99996,0.99973$, respectively.

\subsection{Surface Properties of Inorganic Particles}

To study the effects of the interaction between particles and PBMA on the damping property of composites, the results of a specific surface area and pore size tester were analyzed by the BET method; then, the surface areas of particles measured by BET $\left(\mathrm{S}_{\mathrm{BET}}\right)$ can be calculated by:

$$
\begin{gathered}
\frac{\mathrm{P}}{\mathrm{V}\left(\mathrm{P}_{0}-\mathrm{P}\right)}=\frac{1}{\mathrm{~V}_{\mathrm{m}} \times \mathrm{C}}+\frac{\mathrm{C}-1}{\mathrm{~V}_{\mathrm{m}} \times \mathrm{C}} \times\left(\mathrm{P} / \mathrm{P}_{0}\right) \\
\mathrm{S}_{\mathrm{BET}}=\mathrm{V}_{\mathrm{m}} \times \mathrm{A} \times \sigma_{\mathrm{m}}
\end{gathered}
$$

where:

- $\quad \mathrm{V}_{\mathrm{m}} \rightarrow$ single layer adsorption volume

- $\mathrm{V} \rightarrow$ all adsorption volume

- $\quad \mathrm{P} \rightarrow$ partial pressure of adsorption thing

- $\quad \mathrm{P}_{0} \rightarrow$ saturated vapor pressure of adsorption thing

- $\quad \mathrm{C} \rightarrow$ BET constant

- $\mathrm{A} \rightarrow$ Avogodro constant $\left(6.023 \times 10^{23} / \mathrm{mol}\right)$

- $\sigma_{\mathrm{m}} \rightarrow$ the sectional area of an adsorption thing (for the adsorption of $\mathrm{N}^{2}, \sigma_{\mathrm{m}}=16.2 \times 10^{-20} \mathrm{~m}^{2}$ ).

Thus, the $\left(\mathrm{P} / \mathrm{P}_{0}\right) / \mathrm{V} \times\left(1-\mathrm{P} / \mathrm{P}_{0}\right)$ vs. $\left(\mathrm{P} / \mathrm{P}_{0}\right)$ should be linearity. The linear fitting was used and the results (BET spectra) are plotted in Figure 8. According to the slope and intercept of these fitting lines, we can obtain the value of $\mathrm{V}_{\mathrm{m}}$. In Figure 8 , all dots can be linearly fitted in some degree $\left(R^{2}>\right.$ 0.9). The values of the surface areas measured by BET $\left(\mathrm{S}_{\mathrm{BET}}\right)$ are listed in Table 5 . According to Table 5 , the $\mathrm{S}_{\mathrm{BET}}$ of GF is larger than that of $\mathrm{Fe}_{3} \mathrm{O}_{4}$, which may be caused by graphene, which has a larger specific surface. Moreover, to better understand the surface distribution of the materials, the spectra of nitrogen absorption and desorption for BET is shown in Figure 9. 
Table 5. Values of $\mathrm{S}_{\mathrm{BET}}$.

\begin{tabular}{cc}
\hline Samples & $\mathrm{S}_{\text {BET }}$ \\
\hline $\mathrm{Fe}_{3} \mathrm{O}_{4}$ & 6.808 \\
$\mathrm{GF}$ & 52.565 \\
\hline
\end{tabular}
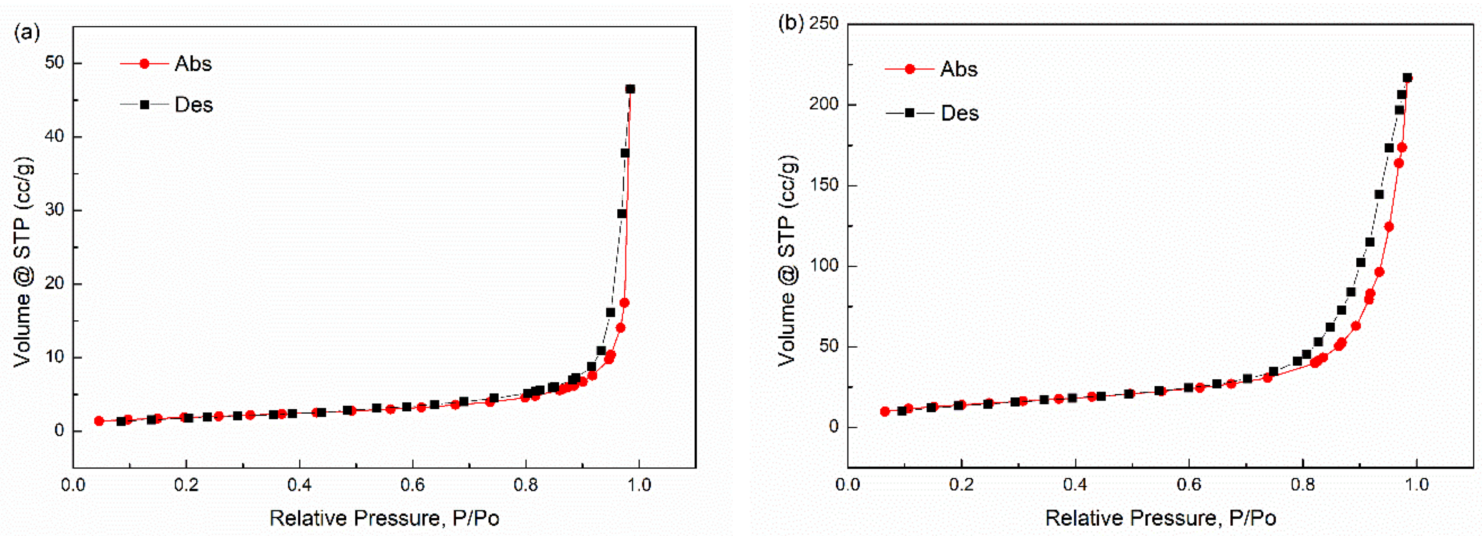

Figure 9. Spectra of nitrogen absorption and desorption trends for BET. (a) $\mathrm{Fe}_{3} \mathrm{O}_{4}$; (b) GF.

\section{Conclusions}

In this study, hybrid composites based on poly(butyl-methacrylate), Ferriferous oxide $\left(\mathrm{Fe}_{3} \mathrm{O}_{4}\right)$, Graphene $/ \mathrm{Fe}_{3} \mathrm{O}_{4}(\mathrm{GF})$, and demagnetization of $\mathrm{Fe}_{3} \mathrm{O}_{4}\left(\alpha-\mathrm{Fe}_{2} \mathrm{O}_{3}\right)$ were successfully prepared. The SEM and EDS results show that Graphene $/ \mathrm{Fe}_{3} \mathrm{O}_{4}$ (GF) was synthesized and that $\alpha-\mathrm{Fe}_{2} \mathrm{O}_{3}$ can be finely dispersed in the PBMA matrix. VSM results revealed that $\alpha-\mathrm{Fe}_{2} \mathrm{O}_{3}$ showed the lowest magnetization after heating at $500{ }^{\circ} \mathrm{C}$. The SEM results show that dispersion of $\alpha-\mathrm{Fe}_{2} \mathrm{O}_{3}$ in the PBMA matrix is better than that of $\mathrm{Fe}_{3} \mathrm{O}_{4}$ and the BET results, exhibiting interfacial interactions between PBMA and GF, is stronger than that between PBMA and $\mathrm{Fe}_{3} \mathrm{O}_{4}$. The DMA results indicate that the damping properties of PBMA can be improved by filling $\mathrm{Fe}_{3} \mathrm{O}_{4}$, GF and $\alpha-\mathrm{Fe}_{2} \mathrm{O}_{3}$. When the weight content of $\alpha-\mathrm{Fe}_{2} \mathrm{O}_{3}$ was $1 \%$, the PBMA $/ \alpha-\mathrm{Fe}_{2} \mathrm{O}_{3}$ had the best damping performance, with the $\tan \delta$ reaching 1.63 and the corresponding temperature range, with $\tan \delta>0.3$, being about $103{ }^{\circ} \mathrm{C}$. Moreover, it is also worth mentioning that the $\mathrm{T}_{\mathrm{g}}$ of the composites shifted to low temperatures. This result needs to be further studied.

Author Contributions: S.Z., J.H. performed the experiments; S.Z. wrote the manuscript; C.Y. conceived and designed the experiments; X.H. contributed to the conception of the study; S.Z. contributed significantly to analysis and manuscript preparation; R.Z. helped perform the analysis with constructive discussions.

Funding: This research was funded by the Science \& Technology Department of Sichuan province (No. 2015JY0052) and the State Key Laboratory of Oil and Gas Reservoir Geology and Exploitation (No. X151516KCL32) of China.

Acknowledgments: The authors thank the Sichuan University for the supply of DMA used in this study.

Conflicts of Interest: The authors declare no conflict of interest.

\section{References}

1. Ahn, S.K.; Jeon, E.; Park, J.; Kim, H.; Kho, H. Investigation of damping in the polymer concrete sleeper for use in reduction of rolling noise from railway. J. Acoust. Soc. Am. 2014, 136, 2209-2210. [CrossRef]

2. Kishi, H.; Kuwata, M.; Matsuda, S.; Asami, T.; Murakami, A. Damping properties of thermoplasticelastomer interleaved carbon fiber-reinforced epoxy composites. Compos. Sci. Technol. 2003, 2003, 2517-2523.

3. Qin, C.L.; Cai, W.M.; Cai, J.; Tang, D.Y.; Zhang, J.S.; Qin, M. Damping properties and morphology of polyurethane/vinyl ester resin interpenetrating polymer network. Mater. Chem. Phys. 2004, 85, 402-409. [CrossRef] 
4. $\quad$ Nashif, A.D.; Jones, D.I.G.; Henderson, J.P. Vibration Damping. J. Vib. Acous. 1987, 109, 240-253. [CrossRef]

5. Ratna, D.; Manoj, N.R.; Chandrasekhar, L.; Chakraborty, B.C. Novel epoxy compositions for vibration damping applications. Polym. Adv. Technol. 2004, 15, 583-586. [CrossRef]

6. Zhang, F.S.; He, G.S.; Xu, K.M.; Wu, H.; Guo, S.Y.; Zhang, C.L. Damping Mechanism and Different Modes of Molecular Motion through the Glass Transition of Chlorinated Butyl Rubber and Petroleum Resin Blends. J. Appl. Polym. Sci. 2014, 131, 378-387. [CrossRef]

7. Ward, I.M.; Sweeney, J. An Introducion to the Mechanical Properties of Solid Polymers. Choice 2004, $12,694$.

8. Li, Z.; Lu, X.; Tao, G.; Guo, J.; Jiang, H. Damping elastomer with broad temperature range based on irregular networks formed by end-linking of hydroxyl-terminated poly(dimethylsiloxane). Polym. Eng. Sci. 2016, 56, 97-102. [CrossRef]

9. Yin, X.; Liu, C.; Lin, Y.; Guan, A.; Wu, G. Influence of hydrogen bonding interaction on the damping properties of poly(N-butyl methacrylate)/small molecule hybrids. J. Appl. Polym. Sci. 2015, 132. [CrossRef]

10. Su, C.; Zong, D.; Xu, L.; Zhang, C. Dynamic mechanical properties of semi-interpenetrating polymer network-based on nitrile rubber and poly(methyl methacrylate-co-butyl acrylate). J. Appl. Polym. Sci. 2014, 131, 742-751. [CrossRef]

11. Borah, J.S.; Chaki, T.K. Dynamic mechanical, thermal, physico-mechanical and morphological properties of LLDPE/EMA blends. J. Polym. Res. 2011, 18, 569-578. [CrossRef]

12. Zhang, R.; He, X.R.; Yu, H. Why tandof poly (butyl acrylate) and poly (ethyl acrylate) with little double bonds are becoming asymmetric? Polymer 2014, 55, 4720-4727. [CrossRef]

13. Li, S.; Zeng, W. Effect of crosslinker, buffer, and blending on damping properties of poly(styrene-acrylonitrile)/ poly(ethyl acrylate- $N$-butyl acrylate) latex interpenetrating polymer networks. J. Appl. Polym. Sci. 2002, 84, 2347-2351. [CrossRef]

14. Li, Y.; Oono, Y.; Nakayama, K.; Shimizu, H.; Inoue, T. Dual lamellar crystal structure in poly(vinylidene fluoride)/acrylic rubber blends and its biaxial orientation behavior. Polymer 2006, 47, 3946-3953. [CrossRef]

15. Zhang, R.; He, X.; Chen, Q.; Feng, C.; Meng, L. Crystallization Kinetics of Functionalized Fe3O4/Ethylene-vinyl Acetate Copolymer Nanocomposites Adhesives. J. Macromol. Sci. Part B 2016, 55, 55-72. [CrossRef]

16. Zhang, R.; He, X.; Lai, Z.; Yang, D. Effect of some inorganic particles on the softening dispersion of the dynamics of butyl rubber. Polym. Bull. 2016, 74, 1-13. [CrossRef]

17. Huang, Z.C.; Liu, W.Q.; Yue, J.J.; Zhou, Q.; Zhang, W.; Lu, Y.; Sui, Y.; Zhai, Y.; Chen, Q.; Dong, S. Enhancing the spin-orbit coupling in $\mathrm{Fe}_{3} \mathrm{O}_{4}$ epitaxial thin films by interface engineering. ACS Appl. Mater. Interfaces 2016, 8, 27354-27359. [CrossRef] [PubMed]

18. He, X.R.; Lu, X.B.; Chen, Q.; Zhang, R. Adhesive and viscoelastic performance of surface functionalized nano- $\mathrm{Fe}_{3} \mathrm{O}_{4}$ induced orientated ethylene vinyl-acetate composite hot melt adhesives. J. Appl. Polym. Sci. 2016, 43931, 1-10.

19. Zhang, Z.; He, X.R.; Zhang, J.J.; Lu, X.B.; Yang, C.H.; Liu, T.; Wang, X.; Zhang, R. Influence of graphene/ferriferrous oxide hybrid particles on properties of nitrile rubber. RSC Adv. 2016, 6, 91798-91805. [CrossRef]

20. Terrier, E.; Liu, Y.; Pichon, B.P.; Bégin-Colin, S.; Halté, V. Ultrafast demagnetization in $\mathrm{Fe}_{3} \mathrm{O}_{4}$ and $\gamma-\mathrm{Fe}_{2} \mathrm{O}_{3}$ nanoparticles: The role of enhanced antiferromagnetic exchange interaction. J. Phys. D Appl. Phys. 2016, 49, 505001. [CrossRef]

21. Can, M.M.; Coşkun, M.; Fırat, T. A comparative study of nanosized iron oxide particles; magnetite $\left(\mathrm{Fe}_{3} \mathrm{O}_{4}\right)$, maghemite $\left(\gamma-\mathrm{Fe}_{2} \mathrm{O}_{3}\right)$ and hematite $\left(\alpha-\mathrm{Fe}_{2} \mathrm{O}_{3}\right)$, using ferromagnetic resonance. J. Alloys Compd. 2012, 542, 241-247. [CrossRef]

22. Wang, Y.; Huang, Y.; Song, Y.; Zhang, X.; Ma, Y.; Liang, J.; Chen, Y. Room-Temperature Ferromagnetism of Graphene. Nano Lett. 2009, 9, 220-224. [CrossRef] [PubMed]

23. Ghasemi, F.A.; Ghorbani, A.; Ghasemi, I. Mech. Mechanical, Thermal and Dynamic Mechanical Properties of PP/GF/xGnP Nanocomposites. Compos. Mater. 2017, 53, 131-138. [CrossRef]

24. Kaneko, H.; Inoue, K.; Tominaga, Y.; Asai, S.; Sumita, M. Damping performance of polymer blend/organic filler hybrid materials with selective compatibility. Mater. Lett. 2002, 52, 96-99. [CrossRef]

25. Rahman, N.A.; Hassan, A.; Yahya, R.; Lafiaaraga, R.A.; Hornsby, P.R. Micro-structural, thermal, and mechanical properties of injection-molded glass fiber/nanoclay/polypropylene composites. J. Reinf. Plast. Compos. 2012, 31, 269-281. [CrossRef] 
26. Zhang, R.; He, X.; Huang, G. Dynamics of Poly (butyl acrylate) and Poly (ethyl acrylate) with internal double bonds. J. Polym. Res. 2014, 21, 1-11. [CrossRef]

27. Cao, F.H.; Wang, J.C. Preparation and characterization of hyperbranched polymer modified montmorillonite/chlorinated butyl rubber damping composites. J. Appl. Polym. Sci. 2016, 133. [CrossRef]

28. Jiang, P.; Yang, C.; He, X.; Rodrigues, A.M.; Zhang, R. Viscoelastic changes in chlorinated butyl rubber modified with graphene oxide. Iran. Polym. J. 2017, 26, 861-870. [CrossRef] 